\title{
Collection of peripheral hematopoietic stem/progenitor cells
}

\author{
Rimajova Dihenescikova V, Mistrik M, Martinka J, Zwiewka M, Bizikova I, Batorova A \\ Clinic of Haematology and Transfusiology, University Hospital, Comenius University, Bratislava, Slovakia. \\ veronika.dihenescikova@gmail.com
}

\begin{abstract}
Objectives: Several variables possibly affecting collection of peripheral hematopoietic stem/progenitor cells (PBSC) were evaluated: type of apheresis machine (Amicus version 2.5, Baxter vs Cobe Spectra version 7.0, Terumo BCT), venous access (peripheral vein vs central venous catheter, i.g. CVC), and apheresis regimen (standard vs large volume leukapheresis, i.g. SVL vs LVL) with the objective to increase collection efficacy at the site.

Background: Peripheral blood represents the currently preferred source of hematopoietic stem/progenitor cells (HSCs) for transplantation.

Methods: Data regarding 169 collection procedures performed in healthy donors and patients between January 2008 and December 2011 at the Clinics of Haematology and Transfusiology in St Cyril and Method Hospital in Bratislava (Slovakia) were analysed.

Results: With Cobe Spectra apheresis machine it was possible to process larger blood volumes per procedure with higher CD34+ cell collection efficiency $(p=0.0229)$ and lower RBC contamination of the harvest than with Amicus $(p=0.0116)$. On the other hand, Amicus helped to limit PLT contamination of the harvest $(p<0.0001)$, thus minimizing post-procedural decrease in patient's PLT count. The highest detected advantage of CVC usage was higher flow rate of procedure, thus processing larger blood volumes per unit of time. Interesting finding was the tendency to lower harvest PLT contamination $(p=0.054)$. When LVL was performed, significantly higher HSCs yields were collected, even in "poor mobilizers" when the pre-run parameters were low.

Conclusion: Management of PBSC collection requires a particular approach in each subject. Institutionally and individually optimized collection may help to improve the transplantation outcome and decrease the financial costs (Tab. 8, Ref. 15). Text in PDF www.elis.sk.

Key words: peripheral hematopoietic stem/progenitor cells, apheresis collection, central venous catheter.
\end{abstract}

Stem cells are unspecialized cells in the human body that are able to develop into specialized cells after recieving the right signal. Hematopoietic stem/progenitor cells (HSCs) are capable to maintain hematopoiesis and to differentiate into all mature peripheral blood cells. Any procedure, where HSCs of any donor and any source are given to a recipient with intention to replace the hematopoietic system in total or in part, is called hematopoietic stem/progenitor cells transplantation. Its development has revolutionized health care, particularly in hematology and oncology. Autologous and allogeneic HSCs transplants have been increasingly performed as an effective curative treatment modality in a variety of disorders, including leukemia, lymphoma, multiple myeloma, bone marrow (BM) failure syndromes, immunodeficiency and genetic disorders.

Transplantation outcome and costs depend, besides other factors, also from the graft characteristics. Sufficient number of good quality HSCs is necessary to ensure a reliable hematopoietic regeneration. A common marker used to identify HSCs in peripheral

Clinic of Haematology and Transfusiology, University Hospital, Comenius University, Bratislava, Slovakia

Address for correspondence: V. Rimajova Dihenescikova, MD, PhD, Clinic of Haematology and Transfusiology, University Hospital Bratislava, Antolska 11, SK-851 07 Bratislava, Slovakia.

Phone: +421.949700848 blood or in the graft is CD34 antigen found on their surface and detected by flow cytometry. Another approach to assess HSCs yield are the in-vitro assays (e.g. CFU - Colony-forming units). However, since CFU assessment takes time, its predictive value for engraftment is more useful in autologous setting, when the cells are planned to be transplanted later. HSCs target dose for transplantation differs according to clinical situation. In autologous setting, most reports suggest an optimal target dose of $5 \times 10^{6}$ CD34+ cells per kilogram of patient's body weight, but with $2 \times 10^{6}$ $\mathrm{CD} 34+$ cells $/ \mathrm{kg}$ acceptable engraftment was attained as well (10, 12). Thus, most centres respect the dose of $2 \times 10^{6} \mathrm{CD} 34+$ cells/ $\mathrm{kg}$ as the minimum threshold for autologous transplantation. In allogeneic setting, most centres respect the dose of $3 \times 10^{6} \mathrm{CD} 34+$ cells $/ \mathrm{kg}$ as the minimum threshold for transplantation. However, higher cell doses $\left(\geq 5 \times 10^{6} \mathrm{CD} 34+\right.$ cells $\left./ \mathrm{kg}\right)$ are associated with better survival, better engraftment and lower costs of post-transplantation care (8). In haplotype mismatched transplants, doses of $\geq 10 \times 10^{6} \mathrm{CD} 34+$ cells $/ \mathrm{kg}$ are used.

Historically, HSCs were harvested from BM. The number of human BM transplantations reached peak in the late 1990's. Afterwards, it has has been declining due to its replacement by alternative HSCs sources, such as peripheral blood and umbilical cord blood. Peripheral blood represents the currently preferred source of HSCs for transplantation (peripheral blood hematopoietic stem/ progenitor cells - PBSC). Before the collection (leukapheresis 
performed by means of apheresis machine) starts, a substantial increase in number of circulating PBSC is needed. Pharmacologically enhanced recruitment of HSCs into peripheral blood is called "mobilization". Classical mobilization strategies include administration of G-CSF (Granulocyte colony-stimulating factor, filgrastim) alone, or in combination with myelosuppressive chemotherapy (CHT+G-CSF). Unfortunately, the „responsiveness“ to standard mobilization regimens varies among individuals. G-CSF based mobilization regimens have a $5 \%$ failure rate among healthy donors, cca $30 \%$ among patients, and up to $60 \%$ in high-risk patients such as those exposed to fludarabine $(6,7,9,15)$. In particular, patients with advanced hematological disorders and malignancies are often ,poor mobilizers“.

Hence, the ability to collect sufficient number of HSCs is influenced by various factors. They can be divided in two groups: variables affecting mobilization and variables affecting apheresis collection. Variables affecting mobilization can be "patient/donor related" (e.g. age, gender, body weight, etc), "disease related" (e.g. diagnosis), "therapy related" (e.g. number and composition of previous CHT cycles, radiotherapy, etc), "mobilization regimen related" (e.g. regimen type, mobilization agents used, dosage, etc) and other. Variables affecting apheresis collection, so called "procedure related variables", include venous access, apheresis device and apheresis regimen used.

In this study, several factors possibly affecting collection outcome were analysed with the objective to develop recommendations for collection practice at the site, in order to increase collection efficacy, improve the patient's outcome and decrease financial costs.

\section{Material and methods}

\section{Data collection}

During the studied period (January 2008 - December 2011), totally 169 collection procedures were performed at the Department of Haematology and Transfusiology in St Cyril and Method Hospital in Bratislava in 126 subjects (50 healthy donors and 76 patients with diagnosis of multiple myeloma, acute leukemia and lymphoma) (Tab. 1). All healthy donors were HLA-identical with recipient (10/10 match). Data were collected retrospectively (January 2008 - August 2008) and prospectively (September 2008 - December 2011). Pre-run parameters in peripheral blood, collection and product characteristics were evaluated after every single collection procedure. Patients and healthy donors gave written informed consent with anonymous data collection and their further statistical analysis. An overview of collected data is shown in Table 2.

Tab. 1. Mobilized subjects and performed procedures.

\begin{tabular}{clcc}
\hline Diagnosis & $\begin{array}{c}\text { Number } \\
\text { of mobilized subjects }\end{array}$ & $\begin{array}{c}\text { Number } \\
\text { of procedures }\end{array}$ \\
\hline 2008-2011 & Multiple myeloma & 51 & 66 \\
& Acute leukemia & 19 & 30 \\
& Lymphoma & 6 & 9 \\
& Healthy donors & 50 & 64 \\
\hline
\end{tabular}

Tab. 2. Collected data.

\begin{tabular}{ll}
\hline Subject's characteristics & $\begin{array}{l}\text { gender, age, body weight, total blood volume, } \\
\text { diagnosis }\end{array}$ \\
\hline $\begin{array}{l}\text { Collection procedure } \\
\text { characteristics }\end{array}$ & $\begin{array}{l}\text { type of apheresis machine, processed blood } \\
\text { volume, venous access, running time, flow } \\
\text { rate, ACD infused }\end{array}$ \\
\hline $\begin{array}{l}\text { Pre-run peripheral blood } \\
\text { samples }\end{array}$ & $\begin{array}{l}\text { WBC count, PLT count, CD34+ cells count } \\
\text { (absolute and relative) }\end{array}$ \\
\hline Product characteristics & $\begin{array}{l}\text { CD34+cell yield, WBC yield, MNC yield, } \\
\text { CFU yield, PLT content, HTC }\end{array}$ \\
\hline
\end{tabular}

* ACD - acid citrate-dextrose solution, WBC - white blood cells, PLT - platelets, $\mathrm{MNC}$ - mononuclear cells, CFU - colony-forming units, HTC - hematocrit

\section{Apheresis technique}

Apheresis collection procedures were initiated when the CD34+ cell count in peripheral blood reached at least $10 \times 10^{6} / \mathrm{L}$, with exception of some patients who seemed to be difficult to mobilize, when the collection was started earlier. A maximum of two apheresis procedures per mobilization attempt were performed in each subject. Periferal venous access was preferred. If this was not adequate to ensure constant inlet blood flow, central venous dialysis catheter was inserted into the lower third of vena cava superior. Apheresis was carried out on two types of apheresis devices available at the site, either on Cobe Spectra version 7.0 (Terumo BCT, Lakewood, Co) or on Amicus version 2.5 (Baxter, Deerfield, IL). As the anticoagulant solution, ACD (Acid citrate-dextrose solution) was used. In case of standard volume leukapheresis, the inlet to ACD ratio was of 12:1. Large volume leukapheresis was performed with the inlet to ACD ratio of 24:1, moreover, heparin was added to the ACD solution (3000 IU Heparin/500 mL ACD) and to collection bag (2000 IU Heparin).

\section{Data evaluation}

Collection (and harvest) characteristics were evaluated with regard to type of apheresis machine (Amicus vs Cobe Spectra), venous access (peripheral vein vs central venous catheter), and type of apheresis regimen (standard volume leukapheresis vs large volume leukapheresis). Totally 144 collection procedures were performed with Cobe Spectra and 25 procedures with Amicus, 122 procedures were performed using peripheral venous access (PV) and 47 procedures via central venous catheter (CVC). Effect of apheresis regimen type was analysed in 144 procedures performed by Cobe Spectra: 53 were standard volume leukapheresis (SVL) and 91 were large volume leukapheresis (LVL). Large volume leukapheresis was defined as processing individual's total blood volume (TBV) more than three times during the procedure. Total blood volume calculation was based on Nadler's formula. Collected cell yields (CD34+ cells, white blood cells - WBC, mononuclear cells - MNC, colony forming units - CFU) were calculated in absolute numbers and per kilogram of recipient's body weight. Collection efficiency for CD34+ cells (CE CD34) has been defined as the number of CD34+ cells collected per volume processed at a given circulating CD34+ cell count (11). Assessment of product's contamination with red blood cells (RBC) was based on product's hematocrit (HTC). Product contamination with platelets (CE PLT) has been defined 
Tab. 3. Subjects and pre-run characteristics with regard to apheresis machine.

\begin{tabular}{|c|c|c|c|c|c|c|}
\hline & \multicolumn{3}{|c|}{ Apheresis machine } & \multicolumn{3}{|c|}{ Venous access } \\
\hline & Cobe Spectra $n=144$ & Amicus $n=25$ & p-value & $\mathrm{PV} n=122$ & CVC $n=47$ & p-value \\
\hline Female/Male (n) & $70 / 74$ & $12 / 13$ & 0.955 & $50 / 72$ & $32 / 15$ & 0.002 \\
\hline \multicolumn{7}{|l|}{ Diagnose (n) } \\
\hline Multiple myeloma & 57 & 9 & \multirow{4}{*}{0.266} & 45 & 21 & \multirow{4}{*}{0.006} \\
\hline Acute leukemia & 29 & 1 & & 16 & 14 & \\
\hline Lymphoma & 7 & 2 & & 5 & 4 & \\
\hline Healthy donors & 51 & 13 & & 56 & 8 & \\
\hline Age (years) & $52(18,71)$ & $53(15,68)$ & 0.461 & $50(15,71)$ & $56(20,67)$ & 0.002 \\
\hline Weight $(\mathrm{kg})$ & $77(48,117)$ & $82(48,108)$ & 0.608 & $79(48,117)$ & $78(49,110)$ & 0.914 \\
\hline WBC count $\left(\times 10^{9} / \mathrm{L}\right)$ & $32.8(4.9,80.0)$ & $35.6(9.4,64.5)$ & 0.494 & $36.5(4.9,80.0)$ & $25.5(6.2,51.0)$ & 0.001 \\
\hline CD34+ cells $\left(\times 10^{6} / \mathrm{L}\right)$ & $47.7(5.2,255.5)$ & $72.1(28.7,161.2)$ & 0.009 & $56.8(6.9,255.5)$ & $44.7(5.2,161.2)$ & 0.041 \\
\hline PLT count $\left(\times 10^{9} / \mathrm{L}\right)$ & $159(12,491)$ & $176(47,326)$ & 0.322 & $180(12,491)$ & $113(12,259)$ & $<0.0001$ \\
\hline
\end{tabular}

* WBC - white blood cells, PLT - platelets

Tab. 4. Procedure and harvest characteristics with regard to apheresis machine.

\begin{tabular}{|c|c|c|c|c|}
\hline & Cobe Spectra $n=144$ & Amicus $\mathrm{n}=25$ & $\mathrm{r}$ & p-value \\
\hline $\mathrm{PV} / \mathrm{CVC}$ & $102 / 42$ & $20 / 5$ & & 0.345 \\
\hline Blood volume processed $(\mathrm{L})$ & $16.9(4.5,36.5)$ & $10.8(4.5,16.3)$ & 17.24 & 0.0001 \\
\hline TBV processed (multiples) & $3.4(0.8,5.2)$ & $2.5(1.3,3.2)$ & 29.06 & $<0.0001$ \\
\hline ACD infused (mL) & $923(253,1635)$ & $968(414,1488)$ & 0.29 & 0.5939 \\
\hline Runnig time (min) & $245(74,432)$ & $250(94,336)$ & 3.68 & 0.0569 \\
\hline Flow rate $(\mathrm{mL} / \mathrm{min})$ & $75(35,110)$ & $80(44,90)$ & 0.07 & 0.7879 \\
\hline CE CD34 (\%) & $40.2(9.5,161.0)$ & $29.1(5.7,52.3)$ & $5.28 \mathrm{~F}(1.163)$ & 0.0229 \\
\hline CE PLT (\%) & $16.0(3.1,35.2)$ & $3.9(1.5,8.5)$ & $92.42 \mathrm{~F}(1.163)$ & $<0.0001$ \\
\hline Decrease in PLT count (\%) & $44(0,81)$ & $10(0,87)$ & $39.88 \mathrm{~F}(1.160)$ & $<0.0001$ \\
\hline $\mathrm{WBC} \times 10^{8}$ & $664(86,2579)$ & $319(102,528)$ & $16.80 \mathrm{~F}(1.163)$ & 0.0001 \\
\hline $\mathrm{WBC} \times 10^{8} / \mathrm{kg}$ & $9.0(0.8,27.6)$ & $3.9(1.2,8.9)$ & $19.78 \mathrm{~F}(1.163)$ & $<0.0001$ \\
\hline $\mathrm{MNC} \times 10^{8}$ & $416(11,2322)$ & $209(78,442)$ & $9.52 \mathrm{~F}(1.158)$ & 0.0024 \\
\hline$\overline{\mathrm{MNC} \times 10^{8} / \mathrm{kg}}$ & $5.4(0.1,57.9)$ & $2.9(0.9,7.5)$ & $5.30 \mathrm{~F}(1.158)$ & 0.0227 \\
\hline CD34+ cells $\times 10^{6}$ & $273(21,1424)$ & $174(44,530)$ & $3.24 \mathrm{~F}(1.163)$ & 0.0735 \\
\hline CD34+ cells $\times 10^{6} / \mathrm{kg}$ & $3.8(0.4,21.3)$ & $2.3(0.5,8.5)$ & $3.73 \mathrm{~F}(1.163)$ & 0.0551 \\
\hline $\mathrm{CFU} \times 10^{4}$ & $19161(342,87787)$ & $10695(1585,49157)$ & $2.18 \mathrm{~F}(1.156)$ & 0.1417 \\
\hline$\overline{\mathrm{CFU} \times 10^{4} / \mathrm{kg}}$ & $242(4,1038)$ & $130(17,927)$ & $2.26 \mathrm{~F}(1.156)$ & 0.1351 \\
\hline HTC & $0.03(0.02,0.33)$ & $0.06(0.02,0.15)$ & $6.52 \mathrm{~F}(1.163)$ & 0.0116 \\
\hline
\end{tabular}

as the number of PLT collected per volume processed at a given circulating PLT count.

\section{Statistical analysis}

Statistical analyses were performed using SPSS version 16.0 for Windows. Data were analysed and compared for statistically significant differences applying different tests in accordance to their characteristics and normality distribution. The $95 \%$ confidence interval and the significance level of 0.05 were set. Data are presented as median, minimum and maximum value.

\section{Results}

Effect of apheresis machine and venous access on procedure and harvest characteristics was evaluated in multivariable analysis. Subjects characteristics and pre-run parameters are detailed in Table 3. Results of analyses are shown in Tables 4 and 5.

Procedures performed with the apheresis machine Cobe Spectra were further assessed with regard to apheresis regimen
(Tabs 6 and 7), focusing subsequently on LVL performance in "poor-mobilizers", defined as subjects with low pre-run CD34+ cell count in peripheral blood, i.e. $<20 \times 10^{6} / \mathrm{L}(3,15)$. Procedure and harvest characteristics are detailed in Table 8.

\section{Discussion}

In the past, several studies were realised comparing PBSC collection features with regard to different apheresis machines, often with contradictory results. In our study, with Cobe Spectra it was possible to process larger blood volumes per procedure $(16.9 \mathrm{~L}$ vs $10.8 \mathrm{~L}, \mathrm{r}=17.24, \mathrm{p}=0.0001)$ with a higher CD34+ cell collection efficiency (CE CD34: $40.2 \%$ vs $29.1 \%, r=5.28, p=0.0229$ ) collecting harvests with lower RBC contamination (HTC: 0.03 vs $0.06, r=6.52, p=0.0116$ ) when compared to procedures performed with Amicus. On the other hand, the use of Amicus helped to limit PLT contamination of the harvest (CE PLT: $16.0 \%$ vs $3.0 \%$, $\mathrm{r}=92.42, \mathrm{p}<0.0001)$, thus minimizing post-procedural fall in patient's PLT count (44\% vs $10 \%, r=39.88, \mathrm{p}<0.0001)$. This 
Tab. 5. Procedure and harvest characteristics with regard to venous access.

\begin{tabular}{|c|c|c|c|c|}
\hline & $\mathrm{PV} n=122$ & $\mathrm{CVC} n=47$ & $\mathrm{r}$ & p-value \\
\hline Cobe/Amicus & $102 / 20$ & $42 / 5$ & & 0.345 \\
\hline Blood volume processed (L) & $14.5(4.5,36.5)$ & $17.4(7.6,28.5)$ & 0.70 & 0.4055 \\
\hline TBV processed (multiples) & $3.0(0.8,5.2)$ & $3.9(1.5,5.2)$ & 0.72 & 0.3981 \\
\hline ACD infused (mL) & $933(253,1635)$ & $932(501,1442)$ & 0.02 & 0.8990 \\
\hline Runnig time (min) & $250(74,432)$ & $231(120,312)$ & 4.94 & 0.0277 \\
\hline Flow rate $(\mathrm{mL} / \mathrm{min})$ & $71(35,110)$ & $89(48,100)$ & 8.02 & 0.0052 \\
\hline CE CD34 (\%) & $38.7(5.7,161.0)$ & $39.6(9.5,81.2)$ & 0.15 & 0.6977 \\
\hline CE PLT (\%) & $15.9(2.3,29.8)$ & $13.5(1.5,35.2)$ & 3.77 & 0.0540 \\
\hline Decrease in PLT count (\%) & $41(0,87)$ & $43(0,62)$ & 0.28 & 0.5977 \\
\hline $\mathrm{WBC} \times 10^{8}$ & $621(86,2579)$ & $528(111,2262)$ & 0.83 & 0.3633 \\
\hline $\mathrm{WBC} \times 10^{8} / \mathrm{kg}$ & $8.8(0.8,26.1)$ & $7.0(1.3,27.6)$ & 0.96 & 0.3296 \\
\hline $\mathrm{MNC} \times 10^{8}$ & $424(11,2322)$ & $320(79,1018)$ & 1.40 & 0.2393 \\
\hline $\mathrm{MNC} \times 10^{8} / \mathrm{kg}$ & $5.5(0.1,57.9)$ & $4.6(0.9,11.9)$ & 0.97 & 0.3252 \\
\hline CD34+ cells $\times 10^{6}$ & $270(39,1424)$ & $244(21,1136)$ & 0.07 & 0.7942 \\
\hline CD34+ cells $\times 10^{6} / \mathrm{kg}$ & $3.6(0.4,21.3)$ & $3.2(0.4,15.6)$ & 0.10 & 0.7486 \\
\hline $\mathrm{CFU} \times 10^{4}$ & $19161(342,87787)$ & $13307(439,54282)$ & 1.02 & 0.3140 \\
\hline $\mathrm{CFU} \times 10^{4} / \mathrm{kg}$ & $225(4,1038)$ & $165(9,798)$ & 1.36 & 0.2451 \\
\hline HTC & $0.04(0.02,0.33)$ & $0.03(0.02,0.15)$ & 1.03 & 0.3106 \\
\hline
\end{tabular}

*PV - peripheral venous access, CVC - central venous catheter, TBV - total blood volume, ACD - acid citrate dextrose solution, CE CD34 - CD34+ cells collection efficiency, PLT - platelets, CE PLT - PLT contamination of the harvest, WBC - white blood cells, MNC - mononuclear cells, CFU - Colony-forming units, HTC - hematocrit

Tab. 6. Subjects and pre-run characteristics with regard to apheresis collection regimen.

\begin{tabular}{|c|c|c|c|}
\hline & SVL $n=53$ & LVL $n=91$ & $\mathrm{p}$-value \\
\hline Female/Male (n) & $24 / 29$ & $46 / 45$ & 0.542 \\
\hline \multicolumn{4}{|l|}{ Diagnose (n) } \\
\hline Multiple myeloma & 15 & 42 & \\
\hline Acute leukemia & 13 & 16 & 0.278 \\
\hline Lymphoma & 3 & 4 & \\
\hline Healthy donors & 22 & 29 & \\
\hline Age (years) & $46(18,67)$ & $53(20,71)$ & 0.023 \\
\hline Weight (kg) & $77(49,117)$ & $77(48,117)$ & 0.956 \\
\hline$\overline{\mathrm{WBC}}$ count $\left(\times 10^{9} / \mathrm{L}\right)$ & $36.6(4.9,80.0)$ & $27.0(6.2,65.8)$ & 0.012 \\
\hline CD34+ cell count $\left(\times 10^{6} / \mathrm{L}\right)$ & $49.9(10.1,255.5)$ & $47.3(5.2,141.6)$ & 0.583 \\
\hline PLT count $\left(\mathrm{x} 10^{9} / \mathrm{L}\right)$ & $157(12,432)$ & $160(12,491)$ & 0.682 \\
\hline
\end{tabular}

* SVL - standard volume leukapheresis, LVL - large volume leukapheresis, WBC - white blood cells, PLT - platelets

important virtue of Amicus was confirmed also in other studies $(2,14)$. Consequently, the use of Amicus is preferable in patients with severe trombocytopenia.

Except the obvious benefits of central venous catheter usage (e.g. lower risk of insufficient blood flow and procedure interruption), the biggest detected advantage was the possibility to perform the procedure with higher flow rate $(71 \mathrm{~mL} / \mathrm{min}$ vs $89 \mathrm{~mL} /$ min, $r=8.02, p=0.0052$ ), thus processing larger blood volume per unit of time. There was not statistically significant difference in the CD34+ cell collection efficiency. Nevertheless, interesting finding is the tendency to lower harvest PLT contamination when CVC is used ( $15.9 \%$ vs $13.5 \%, r=3.77, p=0.054)$. Therefore, CVC usage helps to limit post-procedural decrease in patient's PLT count. This can be particularly beneficial in subjects with initial pre-run thrombocytopenia, especially in case of LVL performance.

Large volume leukapheresis, by processing of larger blood volume (11.5 L vs 19.7 L, p < 0.0001) together with higher CD34+ cell collection efficiency (CE CD34: $38.4 \%$ vs $41.1 \%, p=0.02$ ), enabled to reach significantly higher HSCs yields when compa-
Tab. 7. Collection and harvest characteristics with regard to apheresis collection regimen.

\begin{tabular}{|c|c|c|c|}
\hline & SVL $n=53$ & LVL $n=91$ & p-value \\
\hline $\mathrm{PV} / \mathrm{CVC}$ & $44 / 9$ & $58 / 33$ & 0.014 \\
\hline Blood volume processed (L) & $11.5(4.5,36.5)$ & $19.7(10.2,29.2)$ & $<0.0001$ \\
\hline TBV processed (multiples) & $2.4(0.8,2.9)$ & $4.5(3.0,5.2)$ & $<0.0001$ \\
\hline ACD infused $(\mathrm{mL})$ & $978(253,1635)$ & $909(555,1387)$ & 0.863 \\
\hline Running time (min) & $216(74,312)$ & $265(170,432)$ & $<0.0001$ \\
\hline Flow rates $(\mathrm{mL} / \mathrm{min})$ & $60(35,110)$ & $80(40,103)$ & $<0.0001$ \\
\hline CE CD34 ( \%) & $38.4(11.5,83.0)$ & $41.1(9.5,161.0)$ & 0.02 \\
\hline$\overline{\operatorname{CE} P L T}(\%)$ & $17.9(7.7,28.5)$ & $14.9(3.1,35.2)$ & $<0.0001$ \\
\hline Decrease in PLT count $(\%)$ & $39.9(0,80.9)$ & $48.3(0,79.6)$ & 0.005 \\
\hline $\mathrm{WBC} \times 10^{8}$ & $530(86,1249)$ & $764(189,2579)$ & $<0.0001$ \\
\hline $\mathrm{WBC} \times 10^{8} / \mathrm{kg}$ & $7.4(0.8,17.0)$ & $10.6(3.1,27.6)$ & $<0.0001$ \\
\hline $\mathrm{MNC} \times 10^{8}$ & $356(44.6,1043)$ & $436(11,2322)$ & 0.004 \\
\hline$\overline{\mathrm{MNC} \times 10^{8} / \mathrm{kg}}$ & $4.6(0.4,13.4)$ & $6.1(0.1,57.9)$ & 0.012 \\
\hline CD34+ cells $\times 10^{6}$ & $195(39,832)$ & $350(21,1424)$ & $<0.0001$ \\
\hline CD34+ dose $\times 10^{6} / \mathrm{kg}$ & $2.7(0.4,11.3)$ & $4.9(0.4,21.3)$ & $<0.0001$ \\
\hline $\mathrm{CFU} \times 10^{4}$ & $12157(862,50566)$ & $21902(342,87787)$ & 0.003 \\
\hline$\overline{\mathrm{CFU} \times 10^{4} / \mathrm{kg}}$ & $163(9,903)$ & $298(4,1038)$ & 0.005 \\
\hline HTC & $0.04(0.01,0.33)$ & $0.03(0.02,0.28)$ & 0.584 \\
\hline
\end{tabular}

Tab. 8. SVL vs LVL procedures in „poor mobilizers”.

\begin{tabular}{lccc}
\hline & SVL $n=6$ & LVL $n=17$ & p-value \\
\hline CE CD34 $(\%)$ & $45.6(25.3,54.5)$ & $31.3(12.9,124.9)$ & 0.828 \\
\hline CE PLT $(\%)$ & $12.9(8.8,23.6)$ & $14.6(3.1,21.8)$ & 0.683 \\
\hline CD34+ cells $\times 10^{6}$ & $62(41,119)$ & $99(21,260)$ & 0.046 \\
\hline CD34+ cells $\times 10^{6} / \mathrm{kg}$ & $0.8(0.4,1.5)$ & $1.3(0.4,3.8)$ & 0.035 \\
\hline CFU $\times 10^{4}$ & $1379(862,3876)$ & $6140(873,14677)$ & 0.001 \\
\hline CFU $\times 10^{4} / \mathrm{kg}$ & $18(9,71)$ & $82(18,213)$ & 0.008 \\
\hline HTC & $0.04(0.03,0.08)$ & $0.03(0.02,0.06)$ & 0.118
\end{tabular}

* SVL - standard volume leukapheresis, LVL - large volume leukapheresis, CE CD34 - CD34+ cells collection efficiency, PLT - platelets, CE PLT - PLT contamination of the harvest, CFU - colony-forming units, HTC - hematocrit 
red to SVL (in absolute numbers and per kilogram of recipient's weight; p-value $<0.05$ in all parameters). Higher cell yields in LVL procedures were confirmed also in other studies $(1,13)$. In addition, the harvest contamination with PLT was lower (CE PLT: $17.9 \%$ vs $14.9 \%, \mathrm{p}<0.0001)$. However, processing larger blood volume led to bigger postprocedural decrease in subject's PLT count $(39.9 \%$ vs $48.3 \%, p=0.005)$, thus LVL may represent a considerable risk in patients with initial severe thrombocytopenia.

Focusing on "poor mobilizers", there were no differences in collection efficiency and product contamination when SVL and LVL procedures were compared, but statistically significantly higher HSCs yields were reached in LVL procedures. Although there are discussions, whether LVL is meaningful in "poor mobilizers" due to lower HSCs reserves in BM and subsequent different dynamics of HSCs efflux into the peripheral blood during longlasting procedure, these results suggest that LVL leads to better collection outcome in this group of subjects what is consistent with results of several other studies $(1,4,5)$.

However, the difference is little and further remobilization with different mobilization strategy may lead to more satisfactory results without the need of LVL performance, e.g. remobilization with plerixafor in multiple myeloma and lymphoma patients (6).

\section{Conclusion}

To improve and optimize HSCs mobilization and collection, recommendations, regulations and guidelines should be regularly updated respecting current knowledge and experience. Furthermore, results from this study confirm the hypothesis that management of PBSC collection requires a particular approach in each subject, i.e. the collection should be institutionally and individually optimized. Naturally, in case of "good mobilizers" it can be possible to collect sufficient CD34+ yields regardless the apheresis machine, apheresis regimen and venous access used. However, this individual approach is particularly useful in "poor mobilizers", when every variable affecting collection success can be decisive for its outcome.

Regarding the technical aspects of PBSC collection practice at the site, important facts were revealed, favouring the Cobe Spectra apheresis machine version 7.0, LVL and the usage of CVC when compared to Amicus apheresis machine version 2.5, SVL and peripheral venous access. In case of "poor mobilizers" it is advisable to collect PBSC cells with Cobe Spectra rather than with Amicus. If we consider to perform LVL procedure, special attention should be paid to patients with initially low PLT count. Negative aspects of LVL can be minimized by the use of CVC, which enables setting of higher flow rates, thus shortening the running time and making the procedure more comfortable for donor/patient. Furthermore, CVC helps to minimize postprocedural decrease in patient's PLT count. The decision regarding CVC insertion or LVL performance should be made after careful consideration of possible risks and benefits. A relatively low number of subjects represents the main limitation to perform this study in a more complex manner, focusing on each particular subgroup of subjects that could further meliorate collection efficacy.

\section{References}

1. Abrahamsen JF, Stamnesfet S, Liseth K, Hervig T, Bruserud O. Largevolume leukapheresis yields more viable $\mathrm{CD} 34+$ cells and colony-forming units than normal-volume leukapheresis, especially in patients who mobilize low numbers of CD34+ cells. Transfusion 2005; 45 (2): 248-253.

2. Adorno G, Del Proposto G, Palombi F, Bruno A, Ballatore G, Postorino M, Tendas A, Del Poeta G, Isacchi G, Amadori S. Collection of peripheral progenitor cells: a comparison between Amicus and Cobe-Spectra blood cell separators. Transfus Apher Sci 2004; 30 (2): 131-136.

3. Andreola G, Vanazzi A, Radice D, Babic A, Rabascio C, Negri M, Martinelli G, Laszlo D. Who should be really considered as a poor mobilizer in the plerixafor era? Transfus Apher Sci 2012; 47 (1): 27-32.

4. Crovetti G, Martinelli G. A-HPC collection: large volume or tailored procedure. Drugs and Cell Therapies in Hematology, North America, 1, Oct. 2012. Available at: $<$ http://www.dcth.org/dcth/article/view/dcth.2012.1s.76>.

5. Gasová Z, Marinov I, Vodvárková S, Böhmová M, Bhuyian-Ludvíková Z. PBPC collection techniques: standard versus large volume leukapheresis (LVL) in donors and in patients. Transfus Apher Sci 2005; 32 (2): 167-176.

6. Gertz MA. Current status of stem cell mobilization. Br J Haematol 2010; 150 (6): 647-662.

7. Goterris R, Hernández-Boluda JC, Teruel A, Gómez C, Lis MJ, Terol MJ, Tormo M, Solano C, Arbona C. Impact of different strategies of second-line stem cell harvest on the outcome of autologous transplantation in poor peripheral blood stem cell mobilizers. Bone Marrow Transplant 2005; 36: 847-853.

8. Heimfeld S. Bone marrow transplantation: how important is CD34 cell dose in HLA-identical stem cell transplantation? Leukemia 2003; 17 (5): 856-858.

9. Morgan S, Seymour JF, Grigg A, Matthews JP, Prince HM, Wolf MM, Januszewicz EH. Predictive factors for successful stem cell mobilization in patients with indolent lymphoproliferative disorders previously treated with fludarabine. Leukemia 2004; 18 (5): 1034-1038.

10. Perez-Simon JA, Martin A, Caballero D, Corral M, Nieto MJ, Gonzalez M, Vazquez L, López-Berges C, Cañizo MC, Mateos MV, Orfao A, San Miguel JF. Clinical significance of CD34+ cell dose in long-term engraftment following autologous peripheral blood stem cell transplantation. Bone Marrow Transplant 1999; 24 (12): 1279-1283.

11. Sarkodee-Adoo C, Taran I, Guo C, Buadi F, Murthy R, Cox E, Lopez R, Westphal S, Shope S, O`Connell B, Wethers L, Meisenberg B. Influence of preapheresis clinical factors on the efficiency of $\mathrm{CD} 34+$ cell collection by large-volume apheresis. Bone Marrow Transplant 2003; 31 (10): 851-855.

12. Scheid C, Draube A, Reiser M, Schulz A, Chemnitz J, Nelles S, Fuchs M, Winter S, Wickramanayake PD, Diehl V, Söhngen D. Using at least $5 \times 10(6) / \mathrm{kg}$ CD $34+\mathrm{c}$ cells for autologous stem cell transplantation significantly reduces febrile complications and use of antibiotics after transplantation. Bone Marrow Transplant1999; 23 (11): 1177-1181.

13. Smolowicz AC, Villman K, Tidefelt U. Large-volume apheresis for the harvest of peripheral blood progenitor cells for autologous transplantation. Transfusion 1997; 37 (2): 188-192.

14. Wu FY, Heng KK, Salleh RB, Soh TG, Lee JJ, Mah J, Linn YC, Loh Y, Hwang W, Tan LK, Law P, Goh YT. Comparing peripheral blood stem cell collection using the COBE Spectra, Haemonetics MCS+, and Baxter Amicus. Transfus Apher Sci 2012; 47 (3): 345-350.

15. Wuchter P, Ran D, Bruckner T, Schmitt T, Witzens-Harig M, Neben K, Goldschmidt H, Ho AD. Poor mobilization of hematopoietic stem cells-definitions, incidence, risk factors, and impact on outcome of autologous transplantation. Biol Blood Marrow Transplant 2010; 16 (4): 490-499.

Received August 21, 2013. Accepted September 5, 2013. 